\title{
LA MASORA Y EL INTERCAMBIO DE LARÍNGEAS
}

M.`J. DE AZCÁRRAGA

CSIC. Madrid

La dificultad que entraña pronunciar correctamente las letras laríngeas se ve reflejada, por ejemplo, en este texto del Talmud de Babilonia, tratado Mĕgil.lâ ':

Dijo R. Hiyya' a R. Simeón b. Rabbí: si tú fueras levita no serías apto para el estrado por causa del grueso de tu voz. Él fue y se lo dijo a su padre, quien le respondió: vete y dile, cuando tú llegas al versículo וחכיתי ליחוה [y aguardaré a Yahveh, Is 8,17] no se encuentra quien "ultraje y blasfeme" [Sal 44,17] como tú.

La explicación a esto es que R. Hiyya' no tenía una dicción clara y pronunciaba los n como n, por lo que parecía que decía וחכיתי [y golpearé] ${ }^{2}$.

En el mismo lugar de Mĕgil.la dice R. Assi:

No permitiremos pasar ante el Arca a ningún hombre de Bêt Š̉an $o$ de Haifa o de Tibconim, porque ellos pronuncian el $\kappa$ como $\nu$ y el ע como $\mathrm{N}$.

También encontramos otros textos que nos hablan de diferencias locales en la pronunciación de estas letras. En el Talmud de Jerusalén ${ }^{3} \mathrm{y}$ en el Midraš Rabbâ ${ }^{4}$ leemos que en Arabia el $n$ se pronuncia como $ע$ y el $\nu$ como $n$, o bien que en la Escuela de R. Eliezer el $N$ se lee como y y viceversas.

\footnotetext{
' Pág. 24b.

2 Vid. Minhat Say, Is 8,17.

${ }^{3}$ Sanh X $228 \mathrm{c}$.

4 ספר מדרש רבח על חמשח חומשי תורח וחמש מגלות, Wilna 1885-1887. Vid. Lev Rab 23,3; Rut Rab 5,6.

'Beraḱót 32a.
} 
R. David Qimhî advierte en el Miklklôl ${ }^{6}$ que

es necesario clarificar la lectura de las letras para que no se igualen el $i$ y el $\delta$, el $\delta$ y el $r$, ni el $\kappa$ y el $ע$, el y el $\kappa$, ni el $n$ y el $n$, el $n$ y el $n$, porque si no se pronuncian con claridad y no se hace distinción entre ellas puede incurrirse, a veces, en "ultraje y blasfemia" [Sal $44,17]$.

Estas confusiones que se daban en la lengua hablada han llegado en muchas ocasiones al texto escrito de la Biblia Hebrea. Es necesario acudir a las fuentes masoréticas para poder restaurar, conforme a ellas, la escritura según el TM.

Presento aquí tres palabras con una radical laríngea que han sido transmitidas por algunas versiones, manuscritos, comentarios o traducción reflejando otro sentido de esa raíz, derivado del intercambio de dicha radical laríngea por otra, y cuya masora marca su verdadera lectura en el TM.

El pasaje de Is 19,18, donde el TM dice עיר חהרס (= ciudad de la destrucción), es transmitido como עיר החרס (= ciudad del sol) por $1 \mathrm{Q} I s^{\mathrm{a}}$, Symmaco, Targum, Vulgata y versión árabe ${ }^{7}$ y numerosos manuscritos ${ }^{8}$; esta lectura llega, incluso, a las Biblias de Cantera ${ }^{9}$ y Schökel ${ }^{10}$. La Septuaginta traduce $\alpha \sigma \varepsilon \delta \varepsilon \kappa$, que no coincide con ninguna de las anteriores. Conforme al TM traducen "Aquila, Teodoción y Siriaca Pessito" ".

En el tratado Ménahôt del Talmud de Babilonia ${ }^{12}$ dan esta interpretación:

¿Qué significa עיר החרס? Conforme lo traduce R. Yosef, que dice que "Bêt Šemě̌ está destinada a la destrucción, es decir, es una de

${ }^{6}$ Sefer Miklol, ed. Daniel Bomberg, Venecia 1544, pág. 96b.

${ }^{7}$ Vid. ib., Biblia Hebraica Stuttgartensia (= BHS), ... ediderunt K. ElLIGER et W. RUDOlPH, Textum Masoreticum curavit H. P. RÜGER, Masoram elaboravit G. E. WeIL, Stuttgart 1977.

${ }^{8}$ Vid. ib., B. KenNicotT, Vetus Testamentum Hebraicum cum variis lectionibus, Oxford 1776-1780; G. B. DE-RossI, Variae Lectiones Veteris Testamenti, Parmae 17481788; CH. D. GinsBurg נביאים אחרונים, London 1926.

9 Vid. ib., F. Cantera Burgos y M. Iglesias GonzÁlez, Sagrada Biblia, Madrid 1979.

10 Vid. ib., L. Alonso Schökel y J. Mateos, Nueva Biblia Española, Madrid 1975.

1 F. CANTERA, loc. cit.

12 Pág. 110a. 
ellas» ${ }^{13}$. Pero, ¿de dónde se deduce que חר [= destrucción $]$ significa sol? Es porque está escrito: האומר לחרס ולא יזרח [da órdenes al sol y no sale, Jb 9,7].

Rašî dice: «el Targum de Jonatán trae los dos aspectos..." ${ }^{14}$.

Las MP (masora parva) de los manuscritos de Cairo (C) y Alepo (A) se limitan a señalar que הרס es palabra lêt, o única, en la Biblia, pero la MP de la Biblia de Ben Hayyîm ${ }^{15}$ es más explícita y dice: « הרס, lêt y toda la Biblia חר״. Con esta nota queda perfectamente diferenciado este pasaje de Isaías de los de Jue 8,13; Jue 14,18 y Jb 9,7, arriba citado, cuyo texto dice סר.

Por otra parte, también podemos ver en la Masorah Finalis ${ }^{16}$ y en la Massorah de Ginsburg ${ }^{17}$ una lista de palabras que se leen con $\pi$ y son únicas; entre ellas se encuentra הרס, con lo que la lectura, y por tanto la traducción de esta palabra, queda perfectamente fijada por la masora.

En el pasaje והעבד העיר יעבדוהו (Los trabajadores de la ciudad trabajarán en ella») de Ez 48,19, la palabra יעבדוהו aparece en algunos textos como יאבדוהו (= los destruirá), con intercambio de ע ע ע por $\mathfrak{k}$. Hay que matizar, respecto a los textos, que mientras en algunos la modificación responde a una verdadera variante textual, en otros responde a una sugerencia homilética que sigue el método derásico del 'al-tiqrê, (no leas... sino...), con el que muchas palabras bíblicas son interpretadas y explicadas a base de otras similares, pero que no cambian el texto.

En el primer caso, variante textual, hay que citar los pocos manuscritos a los que aluden Kennicott ${ }^{18}$ y BHS ${ }^{19}$ y el Midras de

\footnotetext{
${ }^{13}$ Vid. ib., Targum.

14 Vid. ib., Perus. Quiere decir que utiliza ambas raíces en la traducción, חרס y סาก.

15 Biblia Rabbinica. A Reprint of the 1525 Venice Edition. Edited by J. BeN HAYYIM IBN ADONIYA (= Ben Hayyim). Introduction by M. Goshen-GotTsTEIN, Jerusalem 1972.

16 Vid. Ben Hayyîm op. cit., vol. IV, pág. 159.

17 The Massorah Compiled from Manuscripts... With an Analytical Table of Contents and Lists of Identified Sources and Parallels by A. DotaN, New York 1975, vol. I, pág. 256.

18 Vid. lb., op. cit.

19 Vid. ib., aparato crítico.
} 
Samuel ${ }^{20}$ que cita este pasaje con dobe variante העבד את העיר יאבדוהו: sobra la palabra את, y יעבדוהו está cambiado en יאבדוחו יעוחו.

Un comentario editado al margen del Talmud de Jerusalén ${ }^{21}$ dice así:

En la Biblia está escrito יעבדוהו, con ע, pero aquí se dice "no leas יעבדוהו יעבוהו", sino con א, sún está en el comentario a Números Rabbâ;

sin embargo, en el texto del Talmud se ve la palabra escrita con ע. Sí es cierto que en Números Rabbâ ${ }^{22}$ y también en el Midraš de Salmos ${ }^{23}$ invitan a leer אבדוהו', lo mismo que los comentaristas del Midraš Rabbâ ${ }^{24}$, tanto en el pasaje de Números que se refiere a este cambio, como en Génesis Rabbâ ${ }^{25}$, donde se cita el pasaje de Ezequiel, y está escrito יעבדוהו sin indicar otra lectura.

La masora es clara. Encontramos a este respecto dos notas masoréticas. Una dice: "dos veces con escritura plena", que se refiere a los casos de $\mathrm{Ez} 48,19$ y Sal 72,11 ${ }^{26}$, y otra nota que dice: "tres veces» ${ }^{27}$ o "tres veces en la forma" ${ }^{28}$, que incluye el caso de Jue 10,6, que es עבדוהו. También contravienen la masora los muchos mss. que escriben יעבדהו, con escritura defectiva, aunque no me he referido a ello porque no varían la raíz עבד, y exceden por tanto los límites de este estudio.

Por último voy a citar el pasaje de 2 Cr 33,13 que dice: ויעתר לו

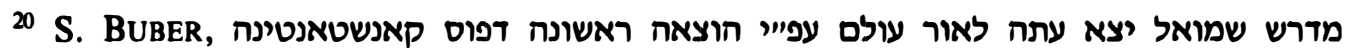
משנת רפייב ודפוס וויניציא משנת שיון, Cracovia 1893, [Reimp. Jerusalem 1965], 28,7, pág. 134.

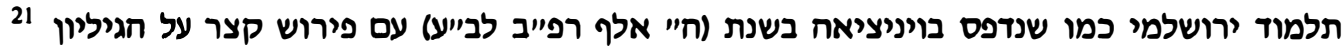
1866, Qid IV 1 65c.

${ }^{22} \mathrm{Ib}, \mathrm{,} \mathrm{8,4}$.

${ }^{23}$ S. BUbER, מדרש תחלים חמכונח שוחר טוב, Vilna 1891 [Reimpr. Jerusalem 1977], 1,10, pág. 10; W. G. BRAUDE, The Midrash on Psalms, New Haven 1959, 17A,14, pág. 226.

${ }^{24}$ Vid. ib., Matěnót Kěhunnah y R. Ze’eb Wolf Einhorn.

${ }^{25} \mathrm{Ib}, \mathrm{,} 20,5$.

26 Vid. MP en los mss. de C y A y Biblia de Ben Hayyîm.

27 Vid. MP del ms. de Leningrado.

${ }^{28}$ Vid. MP BHS; G. E. WeIL, Massorah Gedolah Iuxta Codicem Leningradensem B19a, Roma 1971, MM 1462, pág. 173.

${ }^{29} \mathrm{Vid}$. ib., B. KenNicotT. y Ch. D. GinsBurg, op. cit.
} 
( $=$ y le atendió $)^{30}$, y que se encuentra en algunos textos escrito ויחתר לו (= le hizo una abertura), con intercambio de $n$. Podemos ver esta variante textual en el Targum, en el Talmud de Babilonia ${ }^{31}$ y en algunos códices ${ }^{32}$ y también, según nos dice Norzi ${ }^{33}$, en alguna copia del Perû́s de Rašî. Son muchos los lugares de la literatura rabínica en los que aparece citado este versículo con la palabra ויעתר escrita con ע. Así podemos verlo en el Talmud de Jerusalén ${ }^{34}$ y en el Midraš Rabbâ a Levítico ${ }^{35}$, Números ${ }^{36}$, Deuteronomio ${ }^{37}$ y Rut ${ }^{38}$ así como en los comentarios que acompañan al Midraš ${ }^{39}$, en el Sifrê ${ }^{40}$, en el Yalqût ${ }^{41}$ y en el Pirqê de R. Eliezer ${ }^{42}$; sin embargo, en casi todos ellos el comentario coincide en conectar la raíz עתר con la raíz, y dicen que Dios, siempre misericordioso, hizo una abertura bajo el trono de su gloria para atender la oración de Manasés, ya que los ángeles habían cerrado todas las ventanas y agujeros del cielo para impedirlo. La explicación a este comentario unánime se da en los pasajes ya citados del Talmud de Jerusalén, de Levítico Rabbâ, Rut Rabbâ y del Yalqût que dicen:

en Arabia a una brecha [חתרתה] se le llama עתרתה.

El Midraš de Génesis ${ }^{43}$ relata la parábola del hijo de un rey que "minaba" [חותר] a su padre para que le diera una litra de oro y alude también al intercambio de pronunciación de $n$ y que se daba en Arabia.

La masora dice claramente que la palabra ויעתר, en imperfecto

\footnotetext{
${ }^{30}$ Dios aceptó la oración de Manasés.

31 Sanh 103a.

32 Vid. ib., BHS, B. KenNicotT y Ch. D. GinsBURG, op. cit.

${ }^{33}$ Vid. M. J. De Azcárraga, Minhat Šay de Y. S. de Norzi: Profetas Menores, Madrid 1987, pág. 126, nota 78.

${ }^{34}$ Sanh $\times 228 \mathrm{c}$.

${ }^{35} \mathrm{Ib} ., 30,3$.

${ }^{36} \mathrm{Ib} ., 14,1$.

${ }^{37} \mathrm{Ib} ., 2,20$.

$38 \mathrm{Ib} ., 5,6$.

39 Vid. Matěnót Kěhunnah, Yefeh To'ar y R. Ze'eb Wolf Einhorn.

40 L. Finkelstein: ספרי על ספר דברים, New York 1969, pág. 58 y 407.

41 Livorno [1650]. [Reimpr. New York 1944], pág. 769, remez 246.

42 Pirgé de R. Eliezer, Codex C. H. Horowitz, Jerusalem 1972, pág. 156.

${ }^{43}$ Gen Rab 63,5.
} 
nif'al, aparece cinco veces en la Biblia ${ }^{44}$ : Gen 25,21; 2 Sam 21,14; 2 Sam 24,25; 2 Cr 33,13 y Esd 8,23. Sólo en los pasajes de Crónicas y Génesis aparece en los comentarios el intercambio de $ע$ por $n$, pero mientras en Génesis no es más que un recurso homilético, en Crónicas esta těmûrâ entre dos laríngeas ha llegado a constituir una variante textual.

\section{RESUMEN}

Se presenta el estudio de tres palabras bíblicas con una radical laríngea que han sido transmitidas por algunas versiones, manuscritos, comentarios o traducciones con intercambio de su radical laríngea por otra radical, también laríngea. La masora fija su lectura en el texto masorético.

\section{SUMMARY}

The present study deals with three biblical words bearing a gutural consonant. They have been transmitted by some versions, manuscripts, commentaries or translations, changing their radical gutural consonants for others, also gutural. The masorah sets a precise reading in the masoretic text.

${ }^{44}$ Vid. ib., MP en BHS; MM de Gen 25,21 y 2 Sam 21,14 en Ben Ḩayyîm; $\mathrm{CH}_{\text {. D. }}$ GINSBURG The Massorah, II, pág. 428. 